Brief Report

\title{
Susceptibility of South Texas Aedes aegypti to Pyriproxyfen
}

\author{
Jose G. Juarez ${ }^{1, *}$, Selene M. Garcia-Luna ${ }^{1}$, Christopher M. Roundy ${ }^{1}$, Alyssa Branca ${ }^{2}$, Michael G. Banfield ${ }^{2}$ \\ and Gabriel L. Hamer $1, *$ (D)
}

1 Department of Entomology, Texas A\&M University, College Station, TX 77843, USA; selene.marysol@gmail.com (S.M.G.-L.); cmroundy@tamu.edu (C.M.R.)

2 BanfieldBio Inc., Woodinville, WA 98072, USA; abranca@banfieldbio.com (A.B.); mike@banfieldbio.com (M.G.B.)

* Correspondence: jua05396@tamu.edu (J.G.J.); ghamer@tamu.edu (G.L.H.)

check for

updates

Citation: Juarez, J.G.; Garcia-Luna, S.M.; Roundy, C.M.; Branca, A.; Banfield, M.G.; Hamer, G.L. Susceptibility of South Texas Aedes aegypti to Pyriproxyfen. Insects 2021, 12, 460. https://doi.org/10.3390/ insects 12050460

Received: 31 March 2021

Accepted: 15 May 2021

Published: 17 May 2021

Publisher's Note: MDPI stays neutral with regard to jurisdictional claims in published maps and institutional affiliations.

Copyright: (c) 2021 by the authors. Licensee MDPI, Basel, Switzerland. This article is an open access article distributed under the terms and conditions of the Creative Commons Attribution (CC BY) license (https:// creativecommons.org/licenses/by/ $4.0 /)$.
Simple Summary: We evaluated the susceptibility of an Ae. aegypti strain from the Lower Rio Grande Valley (LRGV) of South Texas to the insect growth regulator pyriproxyfen. We observed a difference in the inhibition of emergence to the lowest doses of pyriproxyfen tested between our field strain and a susceptible strain. However, the doses used are 10 times lower from the recommended application of $<50 \mathrm{ppb}$ for vector control programs. Our results suggest that pyriproxyfen should be an effective active ingredient in the LRGV to help reduce Ae. aegypti populations in the LRGV.

\begin{abstract}
An integral part to integrated mosquito management is to ensure chemical products used for area-wide control are effective against a susceptible population of mosquitoes. Prior to conducting an intervention trial using an insect growth regulator, pyriproxyfen, in South Texas to control Aedes aegypti, we conducted a larval bioassay to evaluate baseline levels of susceptibility. We used seven serially-diluted doses ranging from $2.5 \mathrm{ppb}$ to $6.3 \times 10^{-4} \mathrm{ppb}$. We observed $100 \%$ inhibition emergence (IE) at even the lowest dose of $6.3 \times 10^{-4} \mathrm{ppb}$ in our susceptible reference colony of Ae. aegypti Liverpool. In our field strain of Ae. aegypti (F5 colonized from South Texas) we observed $79.8 \%$ IE at $6.3 \times 10^{-4} \mathrm{ppb}, 17.7 \%$ IE at $1.25 \times 10^{-3} \mathrm{ppb}, 98.7 \%$ IE at $1.25 \times 10^{-2} \mathrm{ppb}$, and $100 \%$ emergence inhibition for the remainder of the doses. Given that commercial pyriproxyfen products are labeled for doses ranging to $50 \mathrm{ppb}$, we conclude that the field population sampled by this study are susceptible to this insect growth regulator.
\end{abstract}

Keywords: Aedes aegypti; pyriproxyfen; emergence inhibition; vector control; autodissemination; insect growth regulator

\section{Introduction}

Aedes aegypti (L.) (Diptera: Culicidae) is an anthropophilic mosquito that is closely associated with urbanized areas across the tropical and subtropical regions of the world. This species has been a major public health concern due to its capacity to transmit arboviruses, such as dengue, chikungunya, yellow fever, and Zika [1]. In the contiguous United States, Ae. aegypti has been reported in Florida and all states that border Mexico [2]. Recently, McGregor and Connelly [3] reviewed chemical control and insecticide resistance studies of Ae. aegypti in the continental U.S. They found a paucity of data on the efficacy and susceptibility of Ae. aegypti to larvicides and emphasized this as a high priority research area.

In the Lower Rio Grande Valley (LRGV) of South Texas, we completed several studies on Ae. aegypti to better understand ecological and social aspects of this mosquito vector $[4,5]$ and to evaluate control tools under local settings [6]. Our research team will conduct an intervention study of Ae. aegypti using pyriproxyfen from autodissemination stations in South Texas. Pyriproxyfen is an insect growth regulator that has been shown to be an effective tool to reduce the emergence of adult Aedes spp. mosquitoes in other geographic 
areas [7-9]. However, before field implementation of pyriproxyfen control tools, the susceptibility status of local Ae. aegypti needs to be assessed. This report presents a laboratory larval bioassay of pyriproxyfen on a recently-colonized population of Ae. aegypti from the LRGV to assess its potential as a control tool for the region.

\section{Materials and Methods}

Ae. aegypti mosquitoes were sampled from a cemetery $\left(26^{\circ} 06^{\prime} 10.91^{\prime \prime} \mathrm{N}, 98^{\circ} 15^{\prime} 16.25^{\prime \prime} \mathrm{W}\right)$ in the city of Mercedes, Texas. Ovitraps (500 mL black cups, with water and hay) were placed in at least five points within the cemetery (100 m apart from each other) from March through July of 2018. Egg papers were retrieved weekly and transported to our insectary facilities in Weslaco, Texas. These samples were reared under laboratory conditions until the fifth filial generation, the colony stablished was referenced as MCF5.

For comparison we used the Ae. aegypti Liverpool strain, as a susceptible reference. We used an oil-based pre-formulation of $20 \%$ technical grade pyriproxyfen (Control Solutions Inc. Pasadena, CA, USA), 12\% Tween 20 (Sigma-Aldrich, St. Louis, MO, USA), and $68 \%$ methylated seed oil (Southern Ag, Rubonia, FL, USA) to prepare a pyriproxyfen stock solution from which seven pyriproxyfen doses $\left(6.3 \times 10^{-4} \mathrm{ppb}, 1.25 \times 10^{-3} \mathrm{ppb}\right.$, $1.25 \times 10^{-2} \mathrm{ppb}, 2.5 \times 10^{-2} \mathrm{ppb}, 6.25 \times 10^{-2} \mathrm{ppb}, 1.25 \times 10^{-1} \mathrm{ppb}, 2.5 \mathrm{ppb}$ ) were prepared $24 \mathrm{~h}$ prior their use. The carrier methylated seed oil and Tween 20 were used in prior studies of autodissemination of pyriproxyfen [8-10]. These doses of pyriproxyfen have been previously observed to generate a mortality range of 10-95\% [11-13] in susceptible strains. For the bioassays, we used 20 third instar larvae at a density of one larva per $10 \mathrm{~mL}$ of water. Four replicates per dose were tested (see Supplementary Dataset 1). Briefly, four sets of $200 \mathrm{~mL}$ of each dose solution or water were placed in plastic cups; subsequently, 20 L3 larvae were added into each cup. Larvae were monitored every $24 \mathrm{~h}$ until all the adults in the absolute control (water) emerged. These methods follow WHO guidelines for larvicide testing [14]. Given the long duration of the test, approximately two drops of liver powder solution $(10 \% w / v)$ were added every other day until pupae were found in the cups. In addition, to assure the oil-based formulation used did not cause mortality, we set up another set of bioassays using the carrier oil alone as the technical control (15\% Tween 20 and 85\% methylated seed oil). For statistical comparison, we used the results observed 12 days post emergence for dead pupae and adults. The data was analyzed using a generalized linear model (GLM) approach with a binomial distribution. We model the interaction effect of dose by strain using the stat and emmeans packages in R. 4.0.4 (R Core Team, Vienna, Austria) (see Supplementary Rcode) $[15,16]$.

\section{Results}

From the seven doses evaluated we were unable to detect a concentration that yielded between 10 and 95\% inhibition of emergence (IE) to determine the IE50 and IE90 values in the susceptible strain (Figure 1). Instead, we observed 100\% IE at even the lowest dose of $6.3 \times 10^{-4} \mathrm{ppb}$ in the susceptible strain. We did not observe any statistical difference for larval or pupal development when comparing the absolute control (water) and the technical control (carrier oil), confirming that the IE observed in the susceptible strain was due to the presence of pyriproxyfen. Our field strain (MCF5) did not show 100\% IE in all doses. We observed 79.8\% IE $(\mathrm{SE}=14.5 \%)$ at $6.3 \times 10^{-4} \mathrm{ppb}, 17.7 \%$ IE $(\mathrm{SE}=15.1 \%)$ at $1.25 \times 10^{-3} \mathrm{ppb}$, and $98.7 \% \mathrm{IE}(\mathrm{SE}=2.6 \%)$ at $1.25 \times 10^{-2} \mathrm{ppb}$ (Figure 1). The GLM analysis showed that if all other variables were held constant, a statistically significant interaction between dose $\left(1.25 \times 10^{-3} \mathrm{ppb}\right)$ and strain (MCF5) (estimate $=-4.321, \mathrm{SE}=1.17$, $p$-value $\leq 0.001)$ was observed. Interestingly, for the MCF5 at a dose of $1.25 \times 10^{-3} \mathrm{ppb}$ we consistently observed a lower IE than that found at the lowest dose of $6.3 \times 10^{-4} \mathrm{ppb}$ (estimate $=2.84, \mathrm{SE}=0.41, p \leq 0.001$ ). Adult emergence in all control groups was $>90 \%$. 


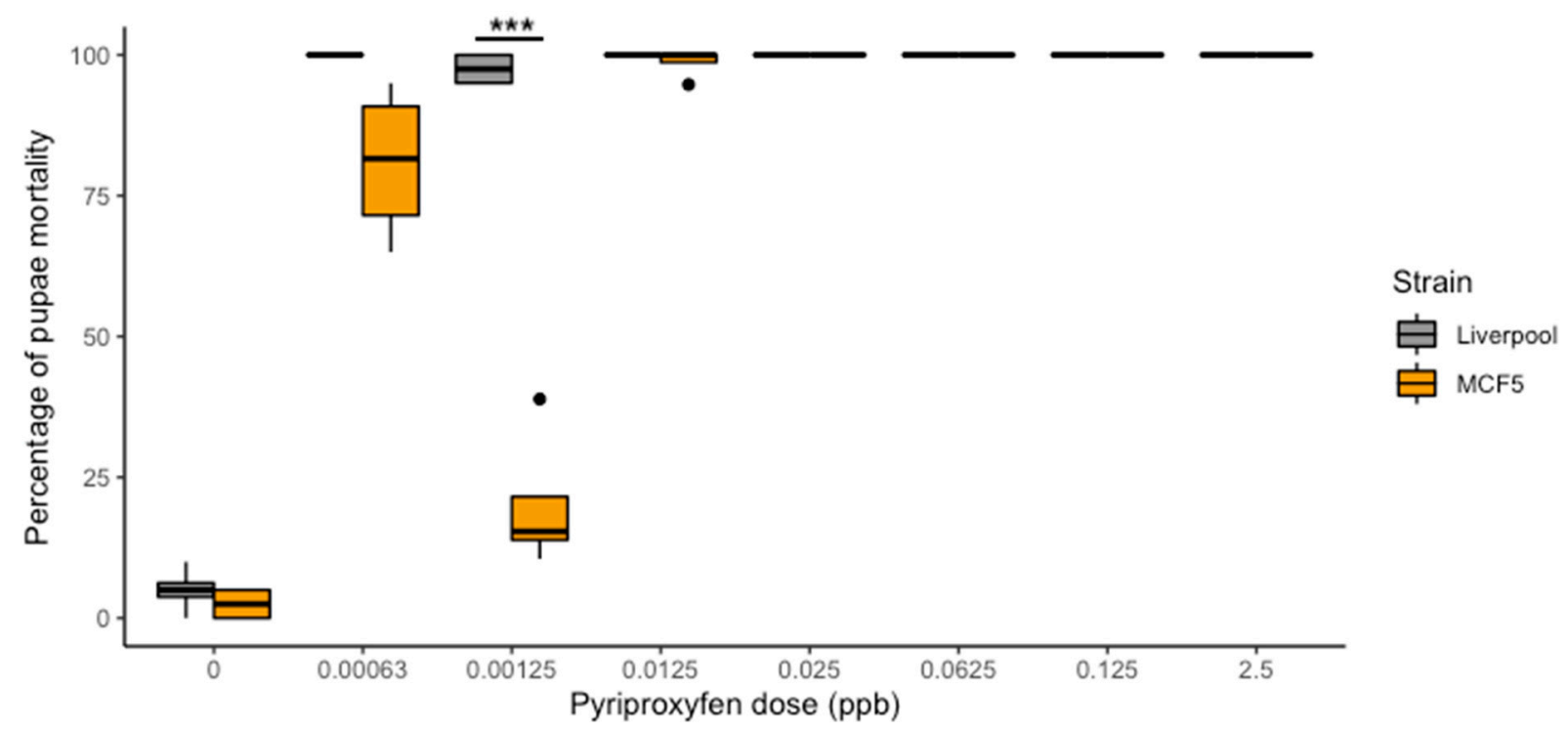

Figure 1. Mortalities induced by pyriproxyfen on the pupae of Ae. aegypti to the Liverpool susceptible strain and the field collected strain (MCF5) from South Texas. ${ }^{* * *}$ Shows statistical significance at $p \leq 0.001$.

\section{Discussion}

Our results show that the South Texas mosquito population MCF5 had resistance at a very low dose of pyriproxyfen that warrants more careful monitoring. We observed a difference in IE for the second lowest doses of the MCF5. Interestingly, we consistently observed a higher IE in the lowest dose tested $\left(6.3 \times 10^{-4} \mathrm{ppb} ; 79.8 \%\right.$ IE) when compared to the second lowest dose $\left(1.25 \times 10^{-3} \mathrm{ppb} ; 17.7 \% \mathrm{IE}\right)$. A pattern that was also observed in the control strain but just marginally. We believe that this might be related to the fine scale regulation that controls ecdysone biosynthesis and how juvenile hormone inhibits it $[17,18]$; the quantity of receptors occupied at this concentration could be ideal, and further doses closer to this range should be explored to elucidate the LD50. However, none of these concentrations used in this study approach the lowest suggested rates of current commercial pyriproxyfen products such as Admiral 10EC (10\% active ingredient (AI)), Admiral Advance $(10 \% \mathrm{AI})$, and NyGuard $(10 \% \mathrm{AI})$, which are tenfold higher or more. Traditionally, mosquito control programs apply pyriproxyfen at a dose of $<50 \mathrm{ppb}$ [19]. These assays show a proof of principle that vector control tools that use pyriproxyfen as an active ingredient could serve as useful tools for controlling Ae. aegypti in the LRGV. Pyriproxyfen is an insect growth regulator that targets immature stages of mosquitoes; it acts at very low doses and it persists for several months in larval habitats [20,21]. Therefore, autodissemination stations that rely on pyriproxyfen might have a meaningful impact as a control tool in areas were source reduction campaigns are unfeasible or cost prohibitive [22]. In addition, integrating additional active ingredients targeting different insect life stages will help to mitigate the development of insecticide resistance. This study did not assess this formulation of pyriproxyfen in the field to estimate the duration of effectiveness. Moreover, this study did not evaluate sublethal doses of pyriproxyfen, which have been documented to increase resistance to pyrethroids in other mosquito species [23]. We point out that the sublethal doses observed in the MCF5 population demonstrate the importance of insecticide resistance surveillance given the potential for the establishment of a resistant wild population. This is particularly relevant to an autodissemination study since exposure to pyriproxyfen in the field is likely to vary among individuals given inconsistent doses to the container habitat. This emphasizes the importance of vector control activities to deliver an adequate dose of insecticide and that failure to do so could enhance the observed resistance. Surveillance for the development of resistance for pyriproxyfen is important as there have been reports of resistance elsewhere in the world $[24,25]$. 
Supplementary Materials: The following are available online at https:/ / www.mdpi.com/article/10.3 390/insects12050460/s1, Dataset 1 and Rcode.

Author Contributions: Conceptualization, S.M.G.-L., A.B., M.G.B., and G.L.H.; methodology, S.M.G.L., A.B., and G.L.H.; validation, S.M.G.-L., J.G.J., A.B., M.G.B., and G.L.H.; formal analysis, J.G.J., S.M.G.-L., and G.L.H.; investigation, S.M.G.-L., J.G.J., A.B., M.G.B., and G.L.H.; resources, M.G.B. and G.L.H.; data curation, J.G.J., S.M.G.-L., C.M.R., and G.L.H.; writing-original draft preparation, J.G.J., S.M.G.-L., and G.L.H.; writing-review and editing, J.G.J., S.M.G.-L., C.M.R., A.B., M.G.B., and G.L.H.; visualization, J.G.J., S.M.G.-L., and C.M.R.; supervision, S.M.G.-L. and G.L.H.; project administration, S.M.G.-L. and G.L.H.; funding acquisition, M.G.B. and G.L.H. All authors have read and agreed to the published version of the manuscript.

Funding: This research was funded by the Centers for Disease Control and Prevention, contract 2002017-93141. Its contents are solely the responsibility of the authors and do not necessarily represent the official views of the Centers for Disease Control and Prevention or the Department of Health and Human Services.

Institutional Review Board Statement: No IRB required.

Data Availability Statement: The datasets are available in the Dataset 1 in Supplementary Material.

Acknowledgments: We would like to thank Ismael Badillo-Vargas for facilitating insectary space at the Texas A\&M AgriLife Research Station in Weslaco, Texas. We thank Edwin Valdez for insectary work during the course of this study.

Conflicts of Interest: The authors declare no conflict of interest. The funders had no role in the design of the study; in the collection, analyses, or interpretation of data; in the writing of the manuscript; or in the decision to publish the results.

\section{References}

1. WHO. Global Vector Control Response 2017-2030; World Health Organization: Geneva, Switzerland, 2017.

2. Hahn, M.B.; Eisen, L.; McAllister, J.; Savage, H.M.; Mutebi, J.P.; Eisen, R.J. Updated reported distribution of Aedes (Stegomyia) aegypti and Aedes (Stegomyia) albopictus (Diptera: Culicidae) in the United States, 1995-2016. J. Med. Entomol. 2017, 54, 1420-1424. [CrossRef]

3. McGregor, B.L.; Connelly, C.R. A Review of the Control of Aedes aegypti (Diptera: Culicidae) in the Continental United States. J. Med. Entomol. 2020. [CrossRef]

4. Olson, M.F.; Garcia-Luna, S.; Juarez, J.G.; Martin, E.; Harrington, L.C.; Eubanks, M.D.; Badillo-Vargas, I.E.; Hamer, G.L. Sugar Feeding Patterns for Aedes aegypti and Culex quinquefasciatus (Diptera: Culicidae) Mosquitoes in South Texas. J. Med. Entomol. 2020, 1-9. [CrossRef] [PubMed]

5. Juarez, J.G.; Garcia-Luna, S.; Chaves, L.F.; Carbajal, E.; Valdez, E.; Avila, C.; Tang, W.; Martin, E.; Barrera, R.; Hemme, R.R.; et al. Dispersal of female and male Aedes aegypti from discarded container habitats using a stable isotope mark-capture study design in South Texas. Sci. Rep. 2020, 10, 6803. [CrossRef]

6. Garcia-Luna, S.M.; Chaves, L.F.; Juarez, J.G.; Bolling, B.G.; Rodriguez, A.; Presas, Y.E.; Mutebi, J.P.; Weaver, S.C.; Badillo-Vargas, I.E.; Hamer, G.L.; et al. From Surveillance To Control: Evaluation of A Larvicide Intervention Against Aedes aegypti In Brownsville, Texas. J. Am. Mosq. Control Assoc. 2019, 35, 233-237. [CrossRef] [PubMed]

7. Maoz, D.; Ward, T.; Samuel, M.; Müller, P.; Runge-Ranzinger, S.; Toledo, J.; Boyce, R.; Velayudhan, R.; Horstick, O. Community effectiveness of pyriproxyfen as a dengue vector control method: A systematic review. PLoS Negl. Trop. Dis. 2017, 11, e0005651. [CrossRef] [PubMed]

8. Chandel, K.; Suman, D.S.; Wang, Y.; Unlu, I.; Williges, E.; Williams, G.M.; Gaugler, R. Targeting a Hidden Enemy: Pyriproxyfen Autodissemination Strategy for the Control of the Container Mosquito Aedes albopictus in Cryptic Habitats. PLoS Negl. Trop. Dis. 2016, 10, e0005235. [CrossRef]

9. Unlu, I.; Suman, D.S.; Wang, Y.; Klingler, K.; Faraji, A.; Gaugler, R. Effectiveness of autodissemination stations containing pyriproxyfen in reducing immature Aedes albopictus populations. Parasites Vectors 2017, 10, 139. [CrossRef]

10. Unlu, I.; Rochlin, I.; Suman, D.S.; Wang, Y.; Chandel, K.; Gaugler, R. Large-scale operational pyriproxyfen autodissemination deployment to suppress the immature asian tiger mosquito (Diptera: Culicidae) Populations. J. Med. Entomol. 2020, 57, 1120-1130. [CrossRef]

11. Sihuincha, M.; Zamora-Perea, E.; Orellana-Rios, W.; Stancil, J.D.; López-Sifuentes, V.; Vidal-Oré, C.; Devine, G.J. Potential use of pyriproxyfen for control of Aedes aegypti (Diptera: Culicidae) in Iquitos, Perú. J. Med. Entomol. 2005, 42, 620-630. [CrossRef]

12. Su, T.; Thieme, J.; Lura, T.; Cheng, M.L.; Brown, M.Q. Susceptibility Profile of Aedes aegypti L. (Diptera: Culicidae) from Montclair, California, to Commonly Used Pesticides, with Note on Resistance to Pyriproxyfen. J. Med. Entomol. 2019, 56, 1047-1054. [CrossRef] [PubMed] 
13. Darriet, F.; Corbel, V. Laboratory evaluation of pyriproxyfen and spinosad, alone and in combination, against Aedes aegypti larvae. J. Med. Entomol. 2006, 43, 1190-1194. [CrossRef] [PubMed]

14. WHO. Guidelines for Laboratory and Field Testing of Mosquito Larvicides; World Health Organization: Geneva, Switzerland, 2005.

15. Lenth, R.; Singmann, H.; Love, J.; Buerkner, P.; Herve, M. Package “emmeans.”. CRAN 2019, 1-75.

16. Faraway, J.J. Extending the Linear Model with R: Generalized Linear, Mixed Effects and Nonparametric Regression Models, 2nd ed.; CRC Press: Boca Raton, FL, USA, 2016; ISBN 978-1498720960.

17. Liu, S.; Li, K.; Gao, Y.; Liu, X.; Chen, W.; Ge, W.; Feng, Q.; Palli, S.R.; Li, S. Antagonistic actions of juvenile hormone and 20-hydroxyecdysone within the ring gland determine developmental transitions in Drosophila. Proc. Natl. Acad. Sci. USA 2018, 115, 139-144. [CrossRef]

18. Bensebaa, F.; Kilani-Morakchi, S.; Aribi, N.; Soltani, N. Evaluation of pyriproxyfen, a juvenile hormone analog, on Drosophila melanogaster (Diptera: Drosophilidae): Insecticidal activity, ecdysteroid contents and cuticle formation. Eur. J. Entomol. 2015, 112, 625-631. [CrossRef]

19. WHO. Report of the Fourth WHOPES Working Group Meeting; World Health Organization: Geneva, Switzerland, 2001.

20. Hustedt, J.C.; Boyce, R.; Bradley, J.; Hii, J.; Alexander, N. Use of pyriproxyfen in control of Aedes mosquitoes: A systematic review. PLoS Negl. Trop. Dis. 2020, 14, 1-18. [CrossRef]

21. Suman, D.S.; Wang, Y.; Faraji, A.; Williams, G.M.; Williges, E.; Gaugler, R. Seasonal field efficacy of pyriproxyfen autodissemination stations against container-inhabiting mosquito Aedes albopictus under different habitat conditions. Pest Manag. Sci. 2018, 74, 885-895. [CrossRef] [PubMed]

22. Yadav, K.; Dhiman, S.; Acharya, B.; Ghorpade, R.R.; Sukumaran, D. Pyriproxyfen treated surface exposure exhibits reproductive disruption in dengue vector Aedes aegypti. PLoS Negl. Trop. Dis. 2019, 13, e0007842. [CrossRef]

23. Opiyo, M.A.; Ngowo, H.S.; Mapua, S.A.; Mpingwa, M.; Matowo, N.S.; Majambere, S.; Okumu, F.O. Sub-lethal aquatic doses of pyriproxyfen may increase pyrethroid resistance in malaria mosquitoes. PLoS ONE 2021, 16. [CrossRef]

24. Carvalho, B.L.; Germano, R.N.L.; Braga, K.M.L.; de Araújo, E.R.F.; Rocha, D.d.A.; Obara, M.T. Susceptibility of Aedes aegypti populations to pyriproxyfen in the federal district of Brazil. Rev. Soc. Bras. Med. Trop. 2020, 53. [CrossRef]

25. Campos, K.B.; Martins, A.J.; de Melo Rodovalho, C.; Bellinato, D.F.; dos Santos Dias, L.; da Graça Macoris, M.D.L.; Andrighetti, M.T.M.; Lima, J.B.P.; Obara, M.T. Assessment of the susceptibility status of Aedes aegypti (Diptera: Culicidae) populations to pyriproxyfen and malathion in a nation-wide monitoring of insecticide resistance performed in Brazil from 2017 to 2018 . Parasites Vectors 2020, 13, 531. [CrossRef] [PubMed] 